\title{
Design and Implementation of Children Safety System using Iot
}

\author{
S.Babu, P. Srivathsava Chowdary, K. Sanjeeth Reddy
}

\begin{abstract}
At this moment structure for growing youth's security is proposed. The accentuation is on the consistently course from home to class and the different way, usage of school transports. IOT perspective is manhandled together with different constraint strategies for instance.RFID and GPS, in order to structure a response for gatekeepers prepared to ensure their youth's following the key steps to class or home, for instance by having the educational transport to login school or exit institution again having transport facility.

At that moment pertinence radio frequency card advancement powerful after capacities attempted in youths' following and seeing during their excursion to and in institution for institution transports. In course of action analyzed with respect to advancements and building and the essential model is presented. Finally a test arranges is needed to check the correct movement of the system.
\end{abstract}

Keywords:

Accentuation,RFID-RadioFrequency Identification,GPS-Global Positioning System,Pertinence.

\section{INTRODUCTION}

Children's security has reliably been a need issue whose course of action ought to consistently be improved. The Savvy Urban areas perspective clearly thinks about the need of giving a continuously positive condition to children's living and learning, yet focusing on this perspective it has moreover to oversee troubles due to urban territories complex circumstances, for instance various structure goals, incalculable running vehicles, swarmed meeting spots and complex personnel structures. Such a space in certainty is normally absent of security conditions for kids, which are unavoidably curious, dynamic, and oblivious (or hurried) of incorporating dangers. As showed by the divided experiences of news reports, the youthful adolescents security accidents starting late can be assembled into four sorts: $34.7 \%$ of disasters happening outside the schools, $11.7 \%$ of children's misconnections, $29.8 \%$ of school transport driver's tactlessness and $23.8 \%$ of children's incidents. Prosperity centered endeavors are directed to use ICT organizations to

Revised Manuscript Received on April 17, 2020.

* Correspondence Author

DR.S.Babu*,CSE,SRMIST,Chennai,India.Email:babu.s@ktr.srmuniv.a c.in

Pathuri. V. V. Srivathsava Chowdary, CSE, SRMIST, Chennai,India.Email:pathurisrivathsava@gmail.com

K.SanjeethReddy,CSE,SRMIST,Chennai,India.Email:sanjeethreddy09 10@gmail.com

(C) The Authors. Published by Blue Eyes Intelligence Engineering and Sciences Publication (BEIESP). This is an open access article under the CC BY-NC-ND license (http://creativecommons.org/licenses/by-nc-nd/4.0/) manufacture secure strategies for decreasing disasters probability. For watchmen the security of their adolescents is pivotal and an insignificant exertion development may give a significant pledge to improve it. One line of experimentation is related to the checking of child's improvements through a structure

including the two GPS (Worldwide Situating Framework) and RFID (Radio Recurrence Distinguishing proof) progresses. The fundamental course of action is abused for school transports limitation, while the second to aggregate information's. Arrangements of security system for children's entering and leaving the school transport. This paper is especially revolved around youths' advancements from home to class entrance, endeavoring to enlighten a little bit of the small children's security issue. A potential request of security structure for youths is appeared in. During the past scarcely any years, in the domain of remote correspondences and frameworks organization, a novel perspective named the Web of Things (IOT) has expanded growing thought both in the insightful network and industry. Starting late, researchers have used the term "Internet of Things" to insinuate the general idea of things.

\section{II. RELATED WORK}

At the present time Franchi proposed a system for extending students protection is proposed. Accentuation consistently place from native into class or the different way, use of school transports. IOT perspective is mishandled together with different limitation methodologies for instance RFID and GPS, to design a response for gatekeepers prepared to ensure student following basic action for class or home, for instance having the educational transport to login school or exit institution again having transport facility. At present time pertinence in radio frequency card advancement beneficial after capacities is attempted in youths' going and viewing during their trip to and from school by school transports. In course game plan discussed the extent that developments and structure and the principle model is presented. Finally a test organize is needed to check the correct action of the structure. Proposed a structure for extending youths' security is proposed. The consideration is on the step by step course from home to class and the different way, usage of school transports. IOT perspective is mishandled together with different constraint methodology for instance RFID and GPS, in order to design a response for gatekeepers prepared to ensure their adolescent's after the crucial to class or home,
Blue Eyes Intelligence Engineering \& Sciences Publication

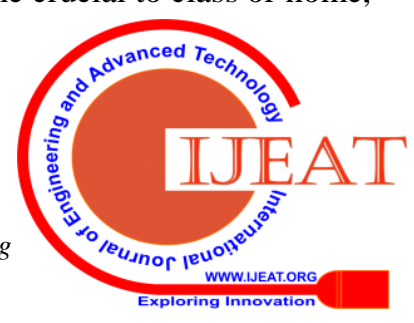


for instance having the educational transport to login school or exit institution again having transport facility. At present time pertinence in radio frequency card advancement beneficial after capacities is attempted in youths' going and viewing during their trip to and from school by school transports. In course game plan discussed the extent that developments and structure and the principle model is presented.

Today in the current overall circumstance, women are going up against various issues like women incitement, stuck between a rock and a hard place and vibrating sensor will send the keep going territory if the device gets slipped off. The essential favored situation of this undertaking is that this device can be passed on any place since it is close to nothing.

In a paper presented by Shi Yanli for following the whereabouts of missing children is a fruitful response for the usage of nonstop information on Web of Things, track find a good pace, development, which utilizes the most conspicuous of RFID radio repeat advancement, which is a non-contact customized ID system. At the present time, mix of the EPC mark chip data scrutinizing, RFID customized acquirement, dispersed stockpiling, remote sensor frameworks and remote arranging and various limits, to repeat the certified scene of the event, and security threats can be pre-check of the looking at proposed course of action. Through the paper, we might want to endeavor to improve, and make reasonable headway and expansion, loss of judicious help to gatherings of adolescents and social understanding and reliability, battling managing of children.

\section{SYSTEM ARCHITECTURE}

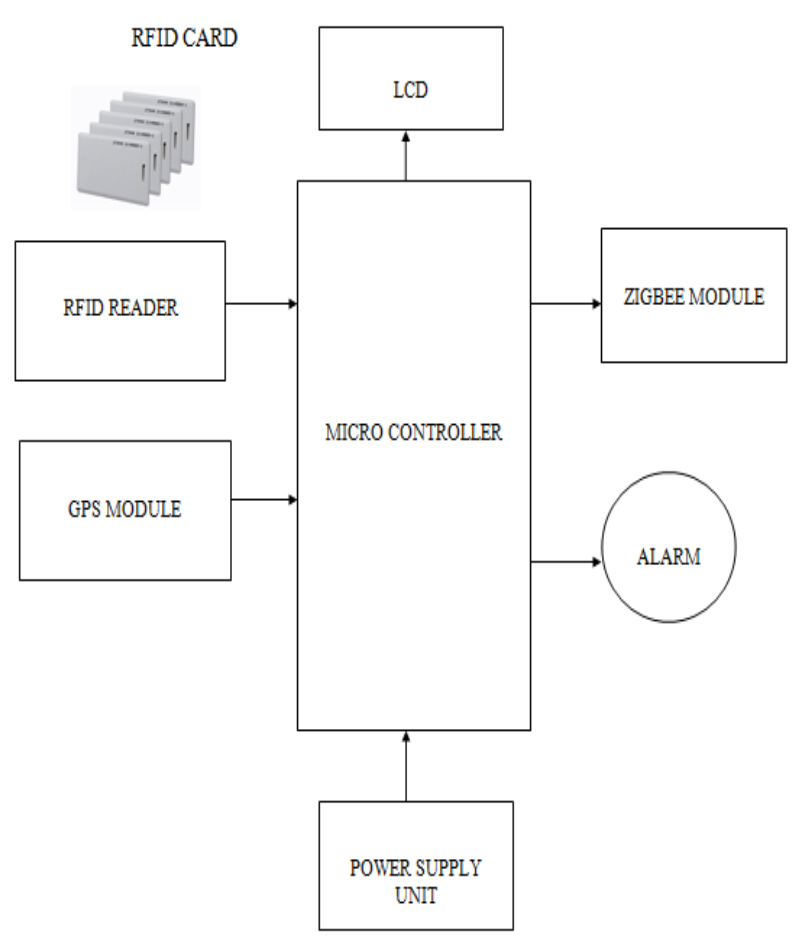

IV. IMPLEMENTATION
A radio repeat recognizing verification per user (RFID per user) contraption aggregate to follow particular things. Radio waves are used to move data from the tag to a per user.

The RFID Per user grouping authority business customized unmistakable confirmation, mechanical innovation, course, stock after, portion structures, and vehicle arrangements names packed.

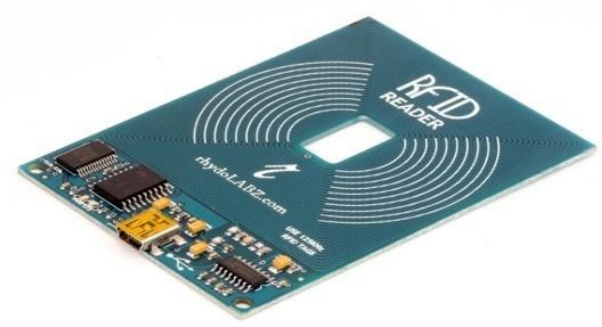

Rfid Reader

A Radio Recurrence ID Per user (RFID per user) move data from the tag to a per user. The RFID mark it must be inside the extent of a RFID per user, to be examined. RFID advancement allows a couple of things to be promptly sifted and engages snappy unmistakable evidence of a particular thing, in any occasion, when it is enveloped by a couple of various things.

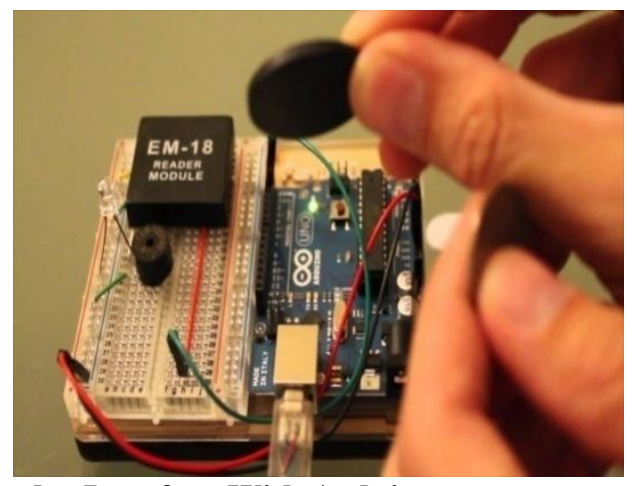

Rfid Reader Interface With Arduino

Radio repeat ID (RFID) is one methodology for Programmed Distinguishing proof and Information Catch (AIDC). RFID marks are used in various endeavors. A RFID structure includes three sections: a receiving wire and handset and a transponder. The gathering device uses radio repeat waves to transmit a sign that starts the transponder. Exactly when ordered, the tag transmits data back to the receiving wire. Radio frequency card per user's function flame broils tag names. Strategies for asking are far away in area of sun present partition commonly low; see difference per user let scores isn't basic. Per user have radio frequency nodes, that moves in common for a sending and incoming of frequencies data. Sending involves sender frequency carrier; accelerator for headings upon this transporter signal and a speaker to assist the adequately sign with stirring the tag. The recipient separator to remove ability that can change getting ready. A chip outlines include by and by fit to be sent to the framework.

\section{A. Rfid Reader}

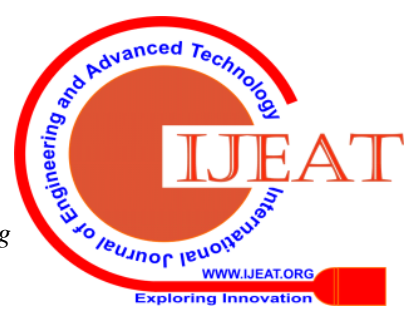




\section{B. Global Position System}

Global located node, at first, is a aerial radio course structure asserted by the US Flying corps. It is an overall catalogue fly system provides earth territory information Global positioning system or near view at any rate fly machine.

Global positioning system doesn't customer send a data, and it works openly of, anyway advances redesign handiness arranging information, essential arranging capacities, normal, and business customers around the world. US take care of it, and make it straightforwardly accessible anyone.

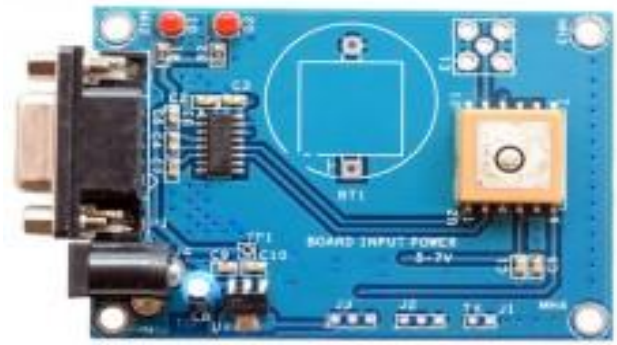

Gps Module

Worldwide Situating Framework an overall course system zone information each and atmosphere. Self-rousingly, anyway progressions update supportiveness arranging information. Information beneficiary in order to evaluate customer's correct place.

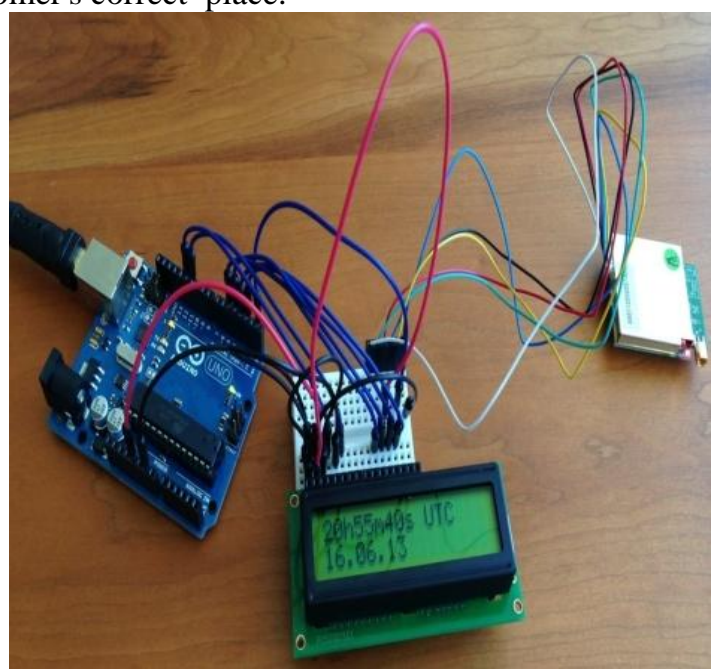

\section{Gps Module Interface With Arduino}

\section{Buzzer}

Ringer, for the most part electronic, ordinarily used in vehicles, nuclear family mechanical assemblies, for instance

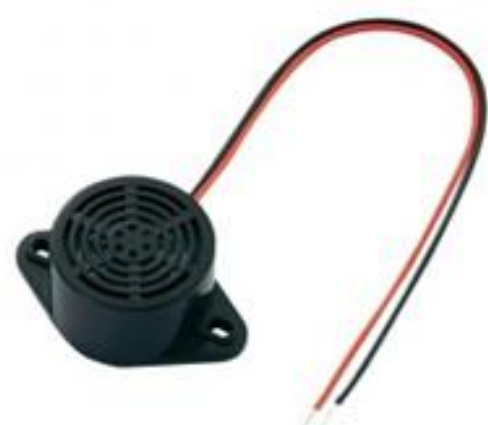

ringer, Ordinary of chimes devices, of customer data, for instance, key stroke.

Ringer, an organized power, comprehensively used in vehicle rigging, timekeepers, sign Appraised really reliable sound, fragment submitted an essential chip plan, "fitting."

\section{RESULTS AND DISCUSSION}
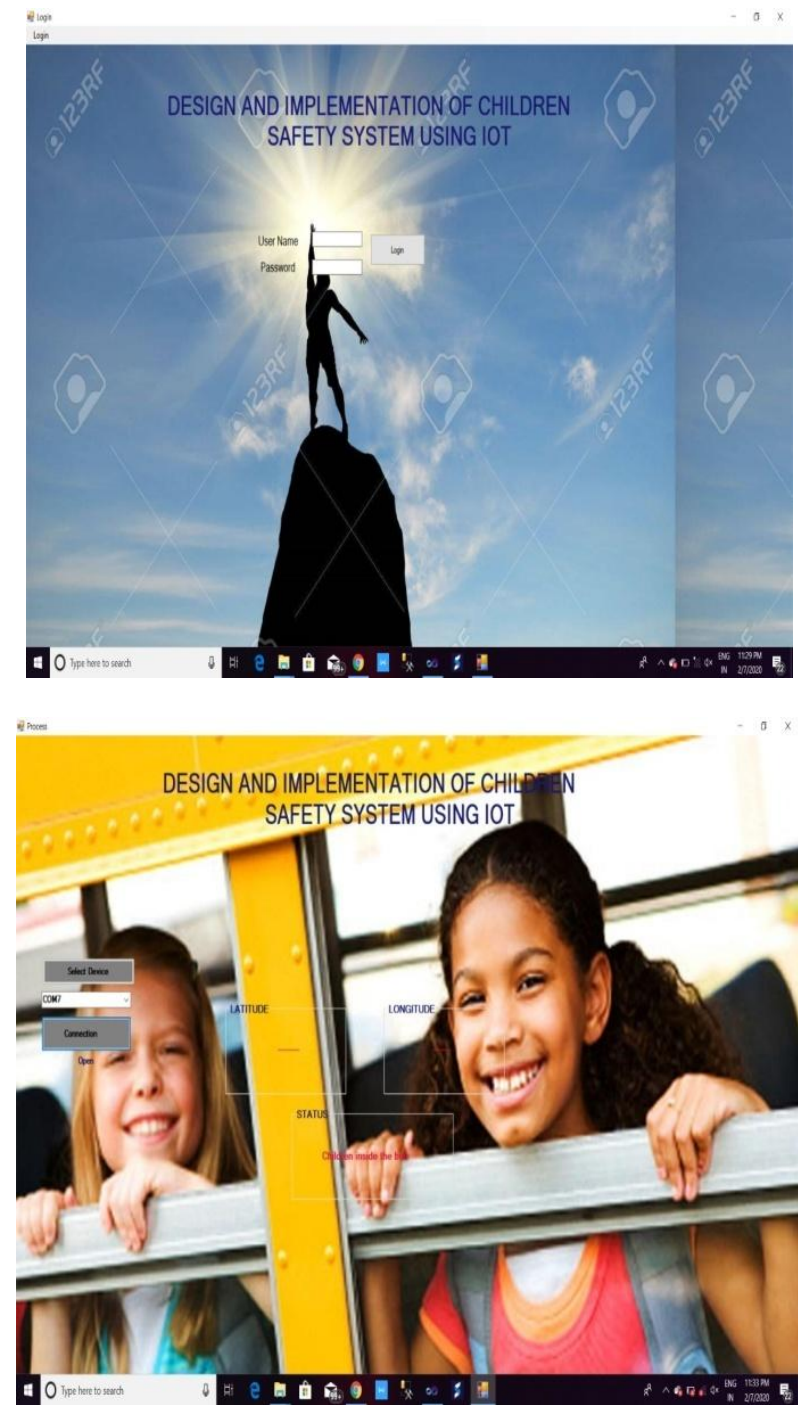

- We can monitor children by attaching RFID tag which helps us in keeping track of them.

- This helps in reducing the cases where people lose their children in crowded places .

- Monitoring of small children is important in crowded places so this would be useful.

Published By:

Blue Eyes Intelligence Engineering \& Sciences Publication

(C) Copyriaht: All rights reserved.

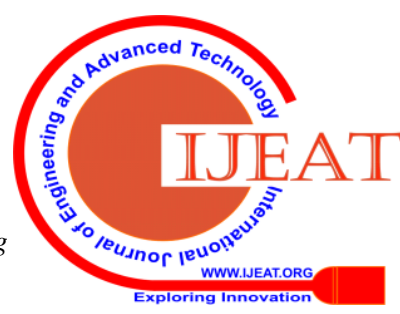


- To ensure the safety of children through tracking.

\section{CONCLUSION}

At this moment system for extending adolescents' security is proposed. The consideration is on the step by step course from home to class and the different way, use of school transports. IoT perspective is mishandled together with different limitation strategies for instance RFID and GPS, to structure a response for gatekeepers prepared to ensure their youth's following the standard strides to class or home, for instance by having the educational transport to login school or exit institution again having transport facility.

At present time pertinence in radio frequency card advancement beneficial after capacities is attempted in youths' going and viewing during their trip to and from school by school transports. In course of action analyzed with respect to advancements and building and the essential model is presented. Finally a test arranges is needed to check the correct movement of the system.

\section{ACKNOWLEDGMENT}

I would like to express my gratitude to all the people behind the screen who helped me to transform an idea into a real application.

My completion of this project could not have been accomplished without the support of my teammate. I would like to thank my internal guide Dr.S.Babu for his technical guidance, constant encouragement and support in carrying out my project at college.

I profoundly thank Dr.B.Amutha, Head of the Department of Computer Science \& Engineering who has been an excellent guide and also a great source of inspiration to my work. I am grateful to our principal, Dr.C.Muthamizhchelvan, who most ably run the institution and has had the major hand in enabling me to do my project.

I would like to express my heart-felt gratitude to my parents without whom I would not have been privileged to achieve and fulfill my dreams.The satisfaction and euphoria that accompany the successful completion of the task would be great but incomplete without the mention of the people who made it possible with their constant guidance and encouragement crowns all the efforts with success. In this context, I would like thank all the other staff members, both teaching and non-teaching, who have extended their timely help and eased my task.

\section{REFERENCES}

1. Minerva, R., Biru, An., and Rotondi, D. (2015). Towards a significance of the Snare of Things (IoT). IEEE Web Movement, Torino, Italy.

2. Stankovic, John. "Research headings for the snare of things." Web of Things Journal, IEEE 1.1 (2014): 3-9.

3. Al-Mazloum, An., E. Omer, and M. F. A. Abdullah. "GPS and SMS-based youth following structure utilizing moved cell." Worldwide Journal of Electrical, Mechanical innovation, Equipment and Exchanges Building 7.2 (2013): 171-174.

4. Yashiro, Takeshi, et al. "A catch of things (IoT) planning for implanted gadgets." Supportive Development Meeting (R10-HTC), 2013 IEEE Area 10. IEEE, 2013.

5. Lee, SeokJu, Girma Tewolde, and Jaerock Kwon. "Structure and execution of vehicle following framework utilizing GPS/GSM/GPRS advancement and PDA application." Web of Things (WF-IoT), 2014 IEEE World Assembling on. IEEE, 2014.

6. Vermesan, Ovidiu, and Reduce Friess, eds. Web of Things-From Investigation and Advancement to Market Association. Conductor Distributers, 2014.
7. Kendall, Steven, Haklin Kimm, and Matthew Jarrell. "Multifunction GPS installed wrist contraption for sprinters." Buyer Devices (ISCE), 2012 IEEE sixteenth All inclusive Symposium on. IEEE, 2012.

8. Zhang, Ruijian. "Applying RFID and GPS tracker for signal preparing in a payload security structure." Signal Planning, Correspondence and Handling (ICSPCC), 2013 IEEE All inclusive Assembling on. IEEE, 2013.

9. Plot Aragón, Jesús, et al. "Inserted microcontroller utilizing GPS as a security asset for injured individuals." Instrumentation and Estimation Development Social occasion (I2MTC) Systems, 2014 IEEE Worldwide. IEEE, 2014.

10. Karimi, Kaivan, and Gary Atkinson. "What the Trap of Things (IoT) needs to change into a reality." White Paper, FreeScale and ARM (2013).

11. Gubbi, Jayavardhana, et al. "Web of Things (IoT): A dream, plan fragments, and future headings." Gathering of individuals yet to come PC Structures 29.7 (2013): 1645-1660.

12. D.Evans, "The Trap of Things - How the Accompanying Progression of the Internet Is Changing Everything",CISCO White Paper,April,2011.

13. P.Elantheirayock,Dr.S.Babu."Smmt Medicine And Physical Health System using IOT"'. International Journal Of Computer Science And Mobile Computing. Vol-4(Issue No-3).

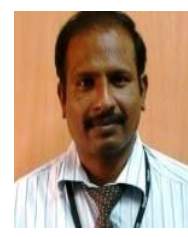

\section{AUTHORS PROFILE}

Dr. S.Babu has studied B.Tech. (IT), M.Tech.(CSE), and obtained Ph.D. in Computer Science \&amp; Engineering from Anna University Chennai, I am Having total teaching experience of 14 years both in UG \&amp; PG Engineering, Also having 6 years of R \&D Experience. Published nearly 6 technical papers in both national and International conference and also published 20 technical papers in International journals. I am the Life member of ISTE and IETE and guiding students for Undergraduate,Postgraduate and Doctoral Program.

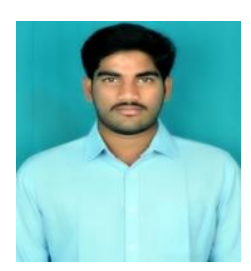

Pathuri V V Srivathsava Chowdary is a Undergraduate Student of batch( 2016-2020) of SRMIST Kattankulathur with and aggregate of 70.42 percent. His areas of interest are Internet of Things,Data warehousing and Mining. Completed a project on Resource Based Time-Sheet Maintenance and Billing Automation System is an online system with 24/7 availability in a Server-Client environment. This software helps in any organization to Manage Projects and Activity Management such as assign activities to employees and to track the activities performed by an employee every day. This helps in deviating Non-billable activities and billable activities performed by an employee.

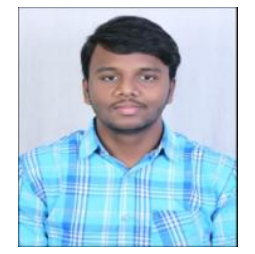

K.Sanjeeth Reddy is a Undergraduate Student of batch( 2016-2020) of SRMIST Kattankulathur with and aggregate of 74 percent. His areas of interest are Internet of Things,Software metrics and quality. He also likes to extend his research in the fields of Virtual Reality,Artificial Intelligence, Cloud Computing,Data Science and Big Data with great enthusiasm.He also completed a project on Smart Irrigation System based on IOT has wide scope to automate the complete irrigation system. It will not only automatically irrigate the water based on the moisture level in the soil but also send the Data to ThingSpeak Server to keep track of the land condition. The System will consist a water pump which will be used to sprinkle water on the land depending upon the land environmental condition such as Moisture, Temperature and Humidity.

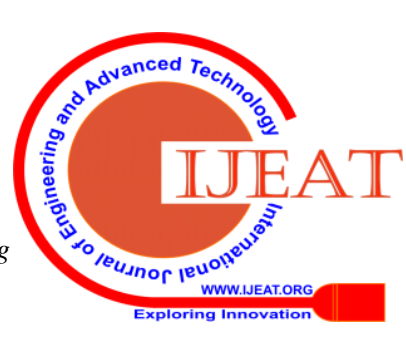

